УДК 621.86

\title{
ПІДВИЩЕННЯ ЕНЕРГОЕФЕКТИВНОСТІ КРАНІВ ШЛЯХОМ ЗАСТОСУВАННЯ ЧАСТОТНО-РЕГУЛЬОВАНОГО ПРИВОДУ
}

Д-р техн. наук О.В. Григоров, старш. викл. В.В. Стрижак, асп. Д.М. Зюбанова

\section{ПОВЫШЕНИЕ ЭНЕРГОЭФФЕКТИВНОСТИ КРАНОВ ПУТЕМ ПРИМЕНЕНИЯ ЧАСТОТНО-РЕГУЛИРУЕМОГО ПРИВОДА}

Д-р техн. наук О.В. Григоров, старш. преп. В.В. Стрижак, асп. Д.М. Зюбанова

\section{ENERGY EFFICIENCY IMPROVEMENT OF CRANES BY THE USE OF VARIABLE- FREQUENCY DRIVE}

Dr. of Science O.V. Grigorov, Senior lecturer V.V. Stryzhak, postgraduate student D.M. Ziubanova

Наведено результати дослідження характеру витрат енергії в частотно-регульованому приводі механізму пересування візка мостового крану. Визначено закономірність зміни співвідношення витрат енергії за робочий ичикл механізму пересування при частотно-регульованому приводі і двигуні з фазним ротором в залежності від тривалості пуско-гальмівних режимів і етапу рівномірного ходу при різних способах гальмування.

Ключові слова: економія енергї, механізм пересування, частотне регулювання.

Приведены результаты исследования характера расхода энергии в частотно-регулируемом приводе механизма передвижения тележки мостового крана. Определены закономерности изменения соотношения затрат энергии за рабочий циикл механизма передвижения при частотно-

Збірник наукових праць УкрДАЗТ, 2014, вип. 148, ч. 1 
регулируемом приводе и двигателе с фазным ротором в зависимости от длительности пускотормозных режимов и этапа равномерного хода при различных способах торможения.

Ключевые слова: экономия энергии, механизм передвижения, частотное регулирование.

The research results of the energy consumption type in the variable-frequency drive of the traveling mechanism of the bridge crane trolley are presented. The regularities of changes in the ratio of energy consumption per working cycle of the traveling mechanism in variable-frequency drive and motor with wound rotor, depending of the start-up and brake modes duration and of the uniform progress stage with varions braking methods, are defined.

Keywords: energy saving, traveling mechanism, frequency regulation.

Постановка проблеми. Вантажопідйомні крани, які обладнані асинхронними двигунами 3 фазним ротором $\epsilon$ не економічними $з$ точки зору споживання енергії. Рішенням цієї проблеми може стати заміна в кранових механізмах асинхронних двигунів 3 фазним ротором на короткозамкнені 3 живленням від частотного перетворювача (частотно-регульований) привід. Однак застосування частотно-регульованого приводу пов'язане 3 відносно великими капітальними витратами, що може бути виправдано зменшенням витрат енергії. Тому $є$ актуальною оцінка витрат енергії частотно-регульованого приводу в механізмах вантажопідйомних машин i порівняння ї 3 витратами асинхронного привода 3 фазним ротором.

Аналіз останніх досліджень i публікацій. Енергетична ефективність частотно-регульованого приводу докладно досліджена i доведена в загальній теорії електроприводу $[1,2]$. Дослідження економії енергії в частотно-регульованому приводі механізмів вантажопідйомних машин можна знайти в роботах [3-7]. Ці дослідження проведені переважно для ліфтів і механізмів підйому, оскільки ці механізми мають можливість рекуперативного гальмування при спуску. Застосування частотно-регульованого приводу в механізмах горизонтального переміщення i повороту також можуть зменшити витрати енергії за рахунок тривалих пуско-гальмівних процесів i використання рекуперативного гальмування [8].

Мета досліджень. Метою дослідження $\epsilon$ зменшення витрат енергії в механізмах пересування шляхом застосування частотнорегульованого приводу.

Виклад основного матеріалу. Дослідження енергетичних характеристик руху частотно-регульованого приводу кранового механізму проводилося на стенді механізму пересування візка мостового крану в/п $32 / 5$ т прогоном 22,5 м (рис. 1), характеристики якого приведені в табл. 1.

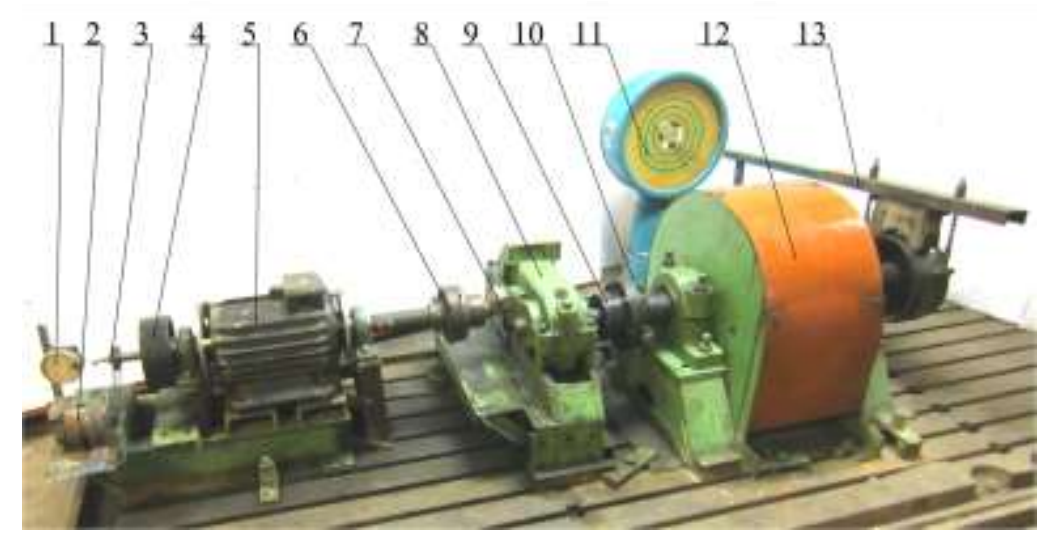

Рис. 1. Стенд для випробування механізму пересування візка мостового крану з частотнорегульованим приводом:

1 - стрілковий тахометр; 2 - тахогенератор; 3 - пасова передача; 4 - шків гальмівний; 5 - електродвигун; 6 - з'єднувальна муфта; 7 - тензодатчики та блок живлення тензодатчиків і підсилення сигналу; 8 - редуктор; 9 - з'єднувальна муфта; 10 - струмознімач; 11 - ваги; 12 - махові маси; 13 - важіль 
На рис. 2 приведено графіки зміни споживаної i рекуперованої потужності частоти струму живлення, швидкості двигуна i крутного моменту впродовж робочого циклу, при якому візок переміщується на відстань характерного робочого ходу 3 максимальним вантажем.

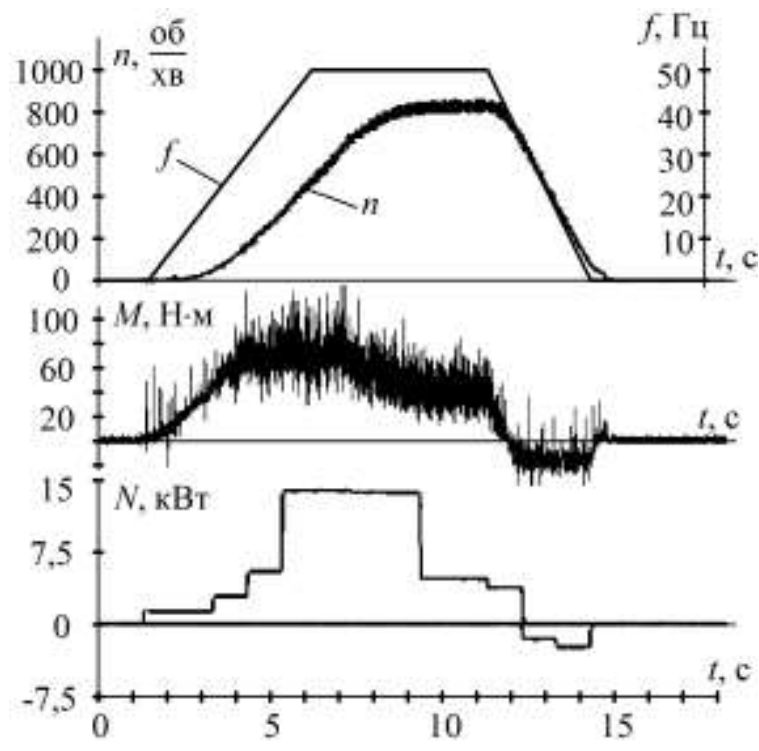

Рис. 2. Графіки зміни частоти струму, швидкості обертання валу двигуна, крутного моменту і споживаної енергії при стендових випробуваннях механізму пересування візка мостового крану з частотно-регульованим приводом при повному завантаженні

За осцилограмою рис. 2 побудована наближена схема зміни потужності, що споживається i рекуперується двигуном впродовж робочого циклу механізму за частотно-регульованого приводу (рис. 3,a). Нижче побудована теоретична схема зміни потужності, що споживається для того ж самого механізму, обладнаного асинхронним приводом 3 фазним ротором (рис. 3,б). Для зручності проведення порівняльного аналізу, контури схем рис. 3,a i 3,6 накладені один на одного на рис. 3 ,в.

3 рис. 3 видно, що частотно-регульований привід має перевагу на етапі розгону i гальмування i програє приводу 3 фазним ротором під час рівномірного ходу, через витрати в частотному перетворювачі. Тому зменшення витрат енергії при застосуванні частотно-регульованого приводу буде варіюватись в широкому діапазоні і залежить від частки пуско-гальмівних етапів в загальному часі робочого циклу механізму. Тому оцінка енергетичної ефективності застосування частотно-регульованого приводу повинна проводитися, беручи до уваги весь робочий цикл механізму з етапами розгону, рівномірного ходу і гальмування.

Провести таку оцінку можна скориставшись методом розрахунку еквівалентної потужності $P_{e}[9,10]$. Для порівняння витрат енергії в обох приводах введемо величину $e$ :

$$
e=\frac{N_{\text {фазн.рот. }}}{N_{\text {част }}}=\frac{P_{e \text { фазн.рот. }} \cdot t_{\text {ц }}}{P_{e \text { част }} \cdot t_{\text {ц }}},
$$

зміст якої буде відображати співвідношення споживання енергії асинхронним приводом 3 фазним ротором і частотно-регульованим за однокового робочого циклу.

Відношення $e$ розраховано для випадку транспортування максимального вантажу за різних режимів гальмування. Характер зміни відношення $e$ від часу рівномірного ходу представлений на рис. 4.

Графіки показують, що для розглядуваного випадку відношення витрат енергії $e \leq 1$ наступає за такої тривалості рівномірного ходу $t_{\text {р.х. }}$, яка рідко зустрічається в практиці експлуатації кранів. Наприклад, для досліджуваного візка тривалість рівномірного ходу при пересуванні на відстань характерного робочого циклу становить $t_{\text {p.х. }}=6,5 \mathrm{c}$.

Висновки. Проведені дослідження дали змогу оцінити зменшення витрат енергії в механізмах пересування 3 частотнорегульованим приводом порівняно 3 асинхронним приводом 3 фазним ротором $\mathrm{i}$ визначити закономірності зміни співвідношення витрат енергії обох типів приводів для різних робочих циклів. 
a)
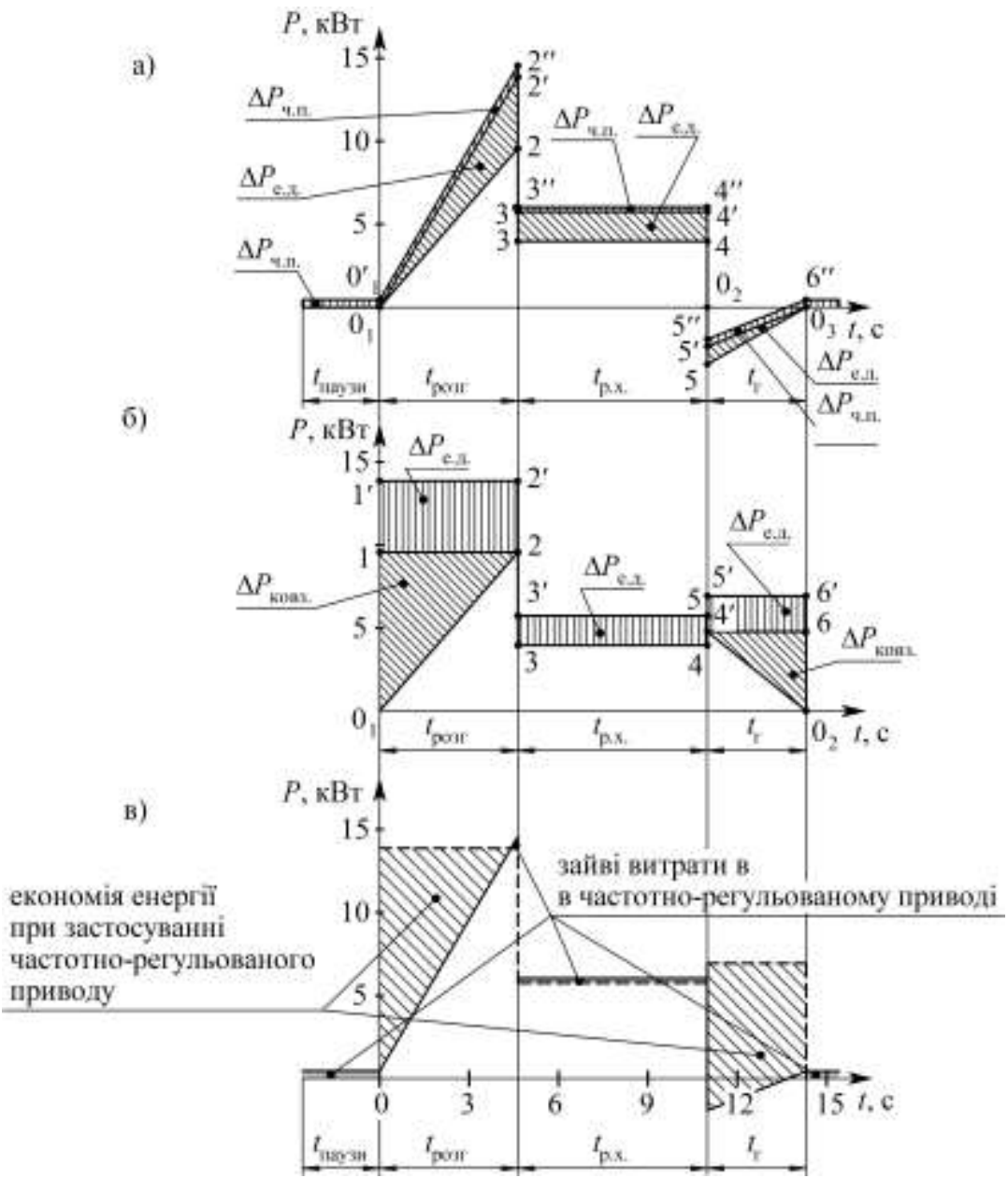

Рис. 3. Схема зміни потужності, що споживається з мережі і рекуперується під час гальмування в механізмі пересування візка мостового крану $32 / 5$ т

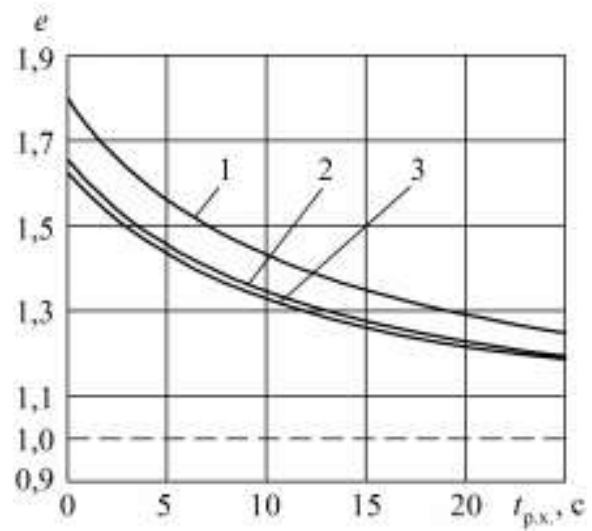

Рис. 4. Графіки співвідношення витрат енергії в механізмі пересування візка мостового крану: 1 - гальмування противключенням; 2 - гальмування механічним гальмом; 3 - гальмування обох приводів механічним гальмом 
Список використаних джерел

1. Браславський, I.Я. Энергосберегающий асинхронный электропривод [Текст] / І.Я. Браславський, 3.Ш. Ішматов, В.Н. Поляков. - М.: «Академия», 2004. - 256 с. $704 \mathrm{c}$.

2. Ключев, В.І. Теория електропривода [Текст] / В.І. Ключев. - М.: Энергоатомиздат, 2001. -

3. Браславський, I.Я. Об эффективности применения частотно-регулируемого электропривода в подъёмно-транспортных машинах [Текст] / І.Я. Браславський, 3.Ш. Ішматов, Ю.В. Плотников // Проблемы автоматизации электропривода. Теория и практика. Вестник НТУ «ХПИ». - Харьков, 2003. - №10. - T.1. - C. 144-145.

4. Певзнер, Є.М. Электрооборудование грузоподъёмных кранов [Текст] / Є.М. Певзнер, Є.В. Попов, М.І. Аксьонов и др. - М.: Россельхозакадемия, 2009. - 360 с.

5. Андрющенко, О.А. Анализ энергетической эффективности электроприводов пассажирских лифтов [Текст] / О.А. Андрющенко, А.О. Бойко, О.Б. Бабийчук // Вісник НТУ «ХПІ». Випуск 28. «Проблеми АЕП. Теорія і практика», 2010. - С. 503-504.

6. Решетняк, С.Н. К вопросу о применении частотно-регулируемого привода шахтных подъемных установок [Текст] / С.Н. Решетняк // Горный информационно-аналитический бюлетень. 2005. - №5. - C. 230-232.

7. Grygorov, O.V. Realization of energy-saving control modes on cranes of great load- carrying capacity / O.V. Grygorov, Y.I. Zaytsev, V.P.Svirgun, V.V. Stryzhak // Revista Minelor - nr. 4/2010 - s.7-14.

8. Григоров, О.В. Енергозбереження шляхом застосування раціонального керування асинхронних електроприводів ВПМ [Текст] / О.В. Григоров, В.П. Свіргун, В.В. Стрижак [та ін.] // Вісник НТУ "ХПІ" "Технології в машинобудуванні". - №49/2010.

9. Чиликин, М.Г. Общий курс электропривода [Текст]: учебник для вузов / М.Г. Чиликин, А.С. Сандлер. - 6-е изд., доп. и перераб. - М.: Энергоиздат, 1981. - 576 с.

10. Блантер, С.Г. Электрооборудование нефтяной и газовой промышленности [Текст] / С.Г. Блантер, И.И. Суд. - 2-е изд., перераб. и доп. — М.: Недра, 1980.

Григоров Отто Володимирович, д-р техн. наук, професор, завідувач кафедрою підйомно-транспортних машин і обладнання Національного технічного університету «Харківський політехнічний інститут».

Стрижак Всеволод Вікторович, старший викладач кафедри підйомно-транспортних машин і обладнання Національного технічного університету «Харківський політехнічний інститут».

Зюбанова Дар'я Михайлівна, аспірантка кафедри підйомно-транспортних машин і обладнання Національного технічного університету «Харківський політехнічний інститут».

Тел.: (057)-70-76-582, (097)-210-34-85.

Grigorov Otto, Ph.D., Professor, manager of department «Hoisting machinery and equipment» National Technical University "Kharkiv Polytechnic Institute".

Stryzhak Vsevolod, Senior Lecturer "Hoisting machinery and equipment» National Technical University "Kharkiv Polytechnic Institute".

Zyubanova Daria, postgraduate student "Hoisting machinery and equipment» National Technical University "Kharkiv

Polytechnic Institute".

Phone: (057) -70-76-582 (097) -210-34-85. 